\title{
Age, growth, mortality and population structure of Strombus canarium (Gastropoda: Strombidae): variations in male and female sub-populations.
}

\begin{abstract}
The age, growth, mortality and population structure of Strombus canarium Linnaeus, 1758 were examined in the Johor Straits, Malaysia from January to December 2005. A total of 2088 conchs were sampled where females were more abundant than males with monthly sex ratio of $1.72 \pm 0.17(\mathrm{~N}=12)$. The estimated growth parameter showed higher asymptotic length $(\mathrm{L} \infty)$ and growth coefficient $(\mathrm{K})$ in females $(\mathrm{L} \infty=70.20 \mathrm{~mm}, \mathrm{~K}=1.50$ year-1) compared with the males $(\mathrm{L} \infty=69.30 \mathrm{~mm}, \mathrm{~K}=1.20$ year-1). This resulted in better overall growth performance of females $\left(\varphi^{\prime}=3.81\right)$ compared with the males $\left(\varphi^{\prime}=3.48\right)$. The growth pattern of females and males showed positive allometric nature of growth $(b>3, p<0.05)$, with estimated maximum life span of 2.0 and 2.5 year, respectively. The recruitment pattern was continuous, displaying only a single major peak event per year. The estimated natural mortality rate $(\mathrm{M})$ was 0.95 year-1 in females and 0.86 year-1 in males, while the total mortality rate $(\mathrm{Z})$ was 2.56 and 2.72 year-1, respectively. The fishing mortality rate $(\mathrm{F})$ was 1.61 year-1 in females and 1.86 year-1 in males, which were higher than the natural mortality rates, thus indicating an unbalanced position of the stock. In addition, the exploitation rate (E) was higher than the maximum allowable limit of exploitation (EMSY), which was a further indication of overexploitation. For sustainable utilization of the resource, serious efforts should immediately be taken in reducing the exploitation rates of S. canarium in the study area.
\end{abstract}

Keyword: Dog conch; ELEFAN-1; FiSAT; Length-weight; VBGF. 